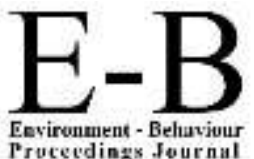

\section{AicE-Bs2019Lisbon}

https://www.amerabra.org; https://fspu.uitm.edu.my/cebs; https://www.emasemasresources.com 9th Asia Pacific International Conference on Environment-Behaviour Studies, Faculty of Architecture, Ulisboa, Lisbon, Portugal, 03-04 Jul 2019

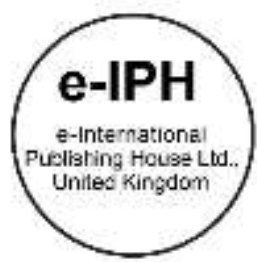

\title{
Children in Urban Space: An Overview
}

\author{
Normah Sulaiman, Filzani Illia Ibrahim \\ School of Architecture, Building and Design, Faculty of Innovation and Technology, \\ Taylor's University, Malaysia \\ Normah.Sulaiman@taylors.edu.my, filzaniillia.ibrahim@taylors.edu.my \\ Tel: $+6012-2880838$
}

\begin{abstract}
This paper will examine the literature review on children in urban space of Kuala Lumpur. Challenges in addressing urban issues vary according to the local context. Urban public spaces in a city did not aim to prioritize children, and it stops them from having independent mobility and freedom to play and socialize. The study will provide a comprehensive review of child-friendly urban spaces intervention focusing on high-rise living in Kuala Lumpur by synthesizing challenges, benefits and recommendations of possible interventions for child-friendly urban spaces. Findings will further enhance the understanding of formulating actions and interventions in creating child-friendly urban spaces.
\end{abstract}

Keywords: child-friendly; urban space; urban sprawls

elSSN: 2398-4287 @ 2019. The Authors. Published for AMER ABRA cE-Bs by e-International Publishing House, Ltd., UK. This is an open access article under the CC BYNCND license (http://creativecommons.org/licenses/by-nc-nd/4.0/). Peer-review under responsibility of AMER (Association of Malaysian Environment-Behaviour Researchers), ABRA (Association of Behavioural Researchers on Asians) and CE-Bs (Centre for Environment-Behaviour Studies), Faculty of Architecture, Planning \& Surveying, Universiti Teknologi MARA, Malaysia.

DOI: https://doi.org/10.21834/e-bpj.v4i11.1734

\subsection{Introduction}

High rise living trend in Malaysia started back in the early 1970s when the rate of urban growth in Malaysia slowly rising from $25 \%$ in 1960s. The percentage keeps rising as there is a vast movement of people to urban areas contributed by factors such as opportunities, work and lifestyle. It is forecast that by the year $2050,70 \%$ of the world population will be living in urban areas. In Malaysia context, approximately 18 million of Malaysian today is living in town and cities. Constructions of a high rise in Malaysia is visible especially on limited prime land in Kuala Lumpur, Selangor and Penang island, making it one of the rapid urbanization for a developing country (Wan Abd Aziz et al., 2014). In these major cities, low-cost housing programs were developed by the State Government for squatters and families affected by urban renewal and development projects. In 1999 alone, a total of 35,000 low-cost housing projects were built as a solution to resettle squatters in urban areas (Ministry of Housing and Local Government Malaysia, 2011). In the long run, this project became a national strategy to curb, resettle and solve squatter issues by State Government. Known as Peoples' Housing Scheme or Program Perumahan Rakyat (PPR), the government see it as a method to enable low-income groups to own houses, live better with minimum acceptable standards, amenities and facilities outside their property. Hence, in the Kuala Lumpur Structure Plan 2020, issues related to these housing scheme often highlights low space standard, maintenance cost, poor quality of constructions and materials. Ministry of Housing Malaysia highlighted that $4 \%$ and rising, is the population of elderly and the disabled in the year 2005; by the year 2020 it will turn into an ageing society, very few lines of their article 3 discusses issues on urban children living in public housing and high rise.

\subsection{Literature Review}

\subsection{Children and Physical Environment.}

eISSN: 2398-4287 @ 2019. The Authors. Published for AMER ABRA CE-Bs by e-International Publishing House, Ltd., UK. This is an open access article under the CC BYNCND license (http://creativecommons.org/licenses/by-nc-nd/4.0). Peer-review under responsibility of AMER (Association of Malaysian Environment-Behaviour Researchers), ABRA (Association of Behavioural Researchers on Asians) and CE-Bs (Centre for Environment-Behaviour Studies), Faculty of Architecture, Planning \& Surveying, Universiti Teknologi MARA, Malaysia.

DOI: https://doi.org/10.21834/e-bpj.v4i11.1734 
Proper urban planning is the foundation for creating a better place for children and families. Jane Jacobs and Kevin Lynch theory gives a positive impact on city planning; however, there is no proper assessment of a positive impact on children. In a report of facing global changes, Jerome Frost (2018) highlighted that child-friendly urban planning could help to achieve city goals and tackle urban challenges by strengthening the links among the built environment, the public realm, and children's wellbeing. To design a city around kids means that it is not just about building more playgrounds, but it is critical that such spaces are needed. For a start, it could focus on two main aspects of the design; everyday freedoms and children's infrastructure. Children' infrastructure refers to the network of spaces and streets that can make a city child- friendly and encourage these everyday freedoms - strategies for how to ensure such child-friendly design focus on walkability and decreasing the dominance of the automobile. Everyday freedoms refer to children's' ability to travel safely on foot or bike and without an adult in their neighbourhood, an example to school or a park. Children fall under the vulnerable group of smaller humans towards vehicle collision due to their inability to judge speed and evaluation of traffic danger. Hence, wider sidewalks and protected bike lanes and footbridges can be one of the practical solutions to prioritize them. An excellent example of such is Barcelona's superblocks - blocks of residential in the city that allows cars to be on perimeter roads and prioritizing more space for pedestrians and cyclists.

\subsection{Children Activity Needs}

To our knowledge, children activities need is that each different age group of children need different activities to be provided. In early years, kids, usually play to explore the senses and creativity and the imagination; at the aged 3-5, opportunities to arouse the curiosity of any toddler and support early development and skills. Children develop the abilities and understanding of concepts and the world around them continue to grow once they are exposed to the school environment. Hence, they engaged more in physical activities and may progress at different rates here. Physical activity plays a vital role in children' physical and mental health, growth and development, cognitive development, improving self-esteem and academic performance (Wong, Parikh, Poh \& Deurenberg, 2016). Between 6-12 yearsold children, their need grows as they understand the play concepts better and more mature with the types of activities that are enjoyable to them. A large body of literature has investigated that physical activity established during childhood benefits children in longevity due to a better lifestyle choice established in their early development (Wong, Parikh, Poh \& Deurenberg, 2016).

\subsection{Methodology}

For a better insight into the matter, research on various discipline is executed. The methods describe actions to be taken to investigate research problems and rationale of the application of specific procedure used to identify, select, process and analyze information to further understands the issue. In the bigger picture, this includes the understanding of the children' housing condition, physical activities, psychological development and environmental characteristics. The methodology applied for this study is desktop research, observational survey and interviews. Desk research includes publication research, book and online research that can provide current and previous information. Observational surveys provide the researcher with the existing condition of the site while interviews with the community further enhance understanding of the subject matter. The chosen research area for this literature study is Batu Muda people's housing scheme. It is in Jalan Ipoh, Sentul Kuala Lumpur adjacent to Kampung Batu Muda. Strategically in the city, these public housings have two main entrances that can bring people into the area. It is also located $770 \mathrm{~m}$ away from the Metropolitan Batu Park, Kepong, a public urban park.

\subsection{Challenges of Child-Friendly Urban Spaces}

In Kuala Lumpur, high-rise living and urban sprawls leads to cramped conditions and reduce the opportunities for children to access to outdoor spaces. Living in low-cost flats constrains children's growing up needs and experiences (Aziz, A.A., and Ahmad, A.S., 2018). This is obvious especially in Batu Muda people's housing scheme where the livelihood assets for a city; does not support the childrens' independent mobility and freedom to play. In fact, it is more difficult for them to socialize and constantly disturbed with current urban development does not consider. It will create impact not just to children but also adults, especially on everyday activities like walking, cycling and play. During the interview, with a small group of community here, they highlighted that the children risk their life crossing highways to get to the nearest Metropolitan park for a better quality of recreational activities. Local authority and community group need to capitalize children as the agent of change for urban development to overcome some of the challenges (Wright, Williams, Hargrave \& Dohna, 2017). Among the challenges of child-friendly urban spaces found are:

\subsection{Housing Condition}

Urban sprawl cause children to be exposed to an environment of car dependency, increased traffic and urban pollution daily. The current public housing condition provides poor quality of green spaces for children to utilize. Studies have reported that local green spaces can promote positive well-being in children although the quantity of green space is insufficient to promote health overall (Flouri, E., Midouhas, E., \& Joshi, H.,2014). Without a well-designed development, children are in a cramped condition and live in isolation and have reduced opportunities for engaging in physical activities and socializing with other children. The existing play area for a high density of population is not enough to cater to the needs for children to be in public space, not to mention it is also poorly maintained.Most importantly, it does not stimulate the well-being of children of the community as the facilities provided only meets the minimum requirement of the development requirement. Most of these people's housing scheme also suffers from poor maintenance of facilities and utilities in the neighbourhood, mainly because of the income level of the community which finds it difficult to finance the monthly maintenance fee. Creative intervention is needed for cheap solutions toward having excellent facilities and at the same time engaged the community to be the caretaker of the facilities, reducing the risk of it from being in a state of despair. From the observations, there is a missing link of providing space for youth 
and the elderly that is also part of the community in Batu Muda people's housing scheme that needs the green space to stay healthy. These are important factors that must be tackled by the local authority and the Ministry of Housing Malaysia and it is time to rethink the people's housing scheme design overall.

\subsection{Physical and Psychological Development}

The research finds that the current condition of public housing does not foster the physical and psychological development of children living there. In a limited space, the opportunities for their discovery are limiting the children's' development. A children's independent mobility and access to urban green space depend entirely on how the parents perceive risk in terms of accidents, crime, strangers and traffic. According to Cities Alive Designing for Urban Childhood, there should be a balanced approach towards all these perception factors in order to encourage exploration and play of children in urban areas. Action needs to be taken to overcome depending and responding correctly to the local context and the city's readiness towards the child-friendly city. From the observation, the community here is conditioned to the physical condition and shapes their psychological development, therefore a change to this condition will take a lot of hard work. In an urban environment, the elements that complete the form and function of it are streets, and the role of the street is only seen to be the major thoroughfare for vehicular traffic (Sulaiman et al., 2017). In the context of Kuala Lumpur and the people's housing scheme, this is a real sight where the volume of the vehicles and the density of living condition is at balance, and this is not good. In America, children's ageing up to 12 years should be supervised in public space. In aid to avoid isolation and intolerance among children, a better street and public space design can foster more interaction and trust. When it comes to the street as public space, Jacobs (2011) theory explains that the streets are an inviting space the most vital organs of the city, its contrast is very dynamic, where the dullness will reflect the city itself. Reflecting from this theory, the observation found that the street within this housing vicinity is designed to accommodate vehicles and it is beyond its capacity. Therefore, it will be challenging to implement this concept to the area as the volume of vehicles within the vicinity is very high and it calls for an alternative intervention.

\subsection{Benefits of Child-Friendly Urban Spaces}

As children grow up, their experiences and perception towards the environment change and for an urban area to be child-friendly, it needs to be able to provide for every phase of child's development (Wright, Williams, Hargrave \& zu Dohna, 2017). A good design of urban space makes people want to stay longer and enjoy the space. The main benefits of having child-friendly urban spaces are explored through some of the case studies from around the world which are suitable to adopt in the local context of public housing scheme in Kuala Lumpur.

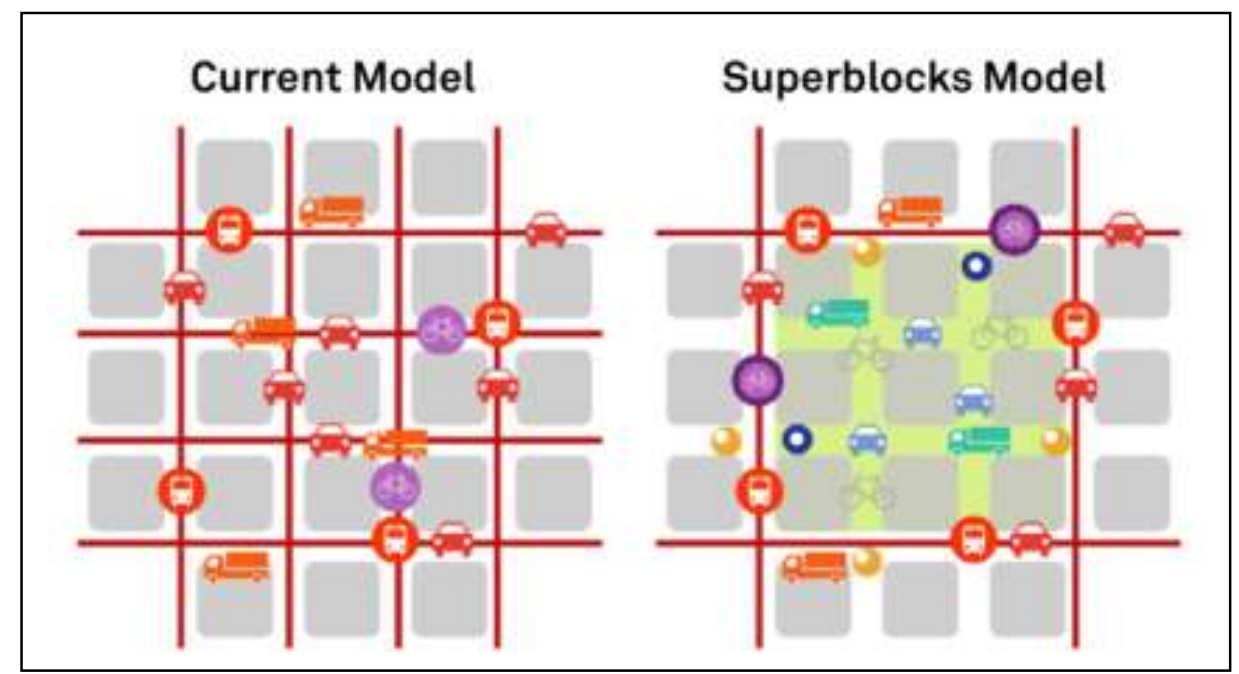

Fig. 1: Superblocks model objective is to revise the street roles in the cities for the people and future. (Source: Bicycle Dutch,2017)

\subsection{Health and Wellbeing}

Barcelona came up with a radical new urban planning idea where they filled the city with life (Robert,2019). Lead by the city's Department of Mobility, traffic to the main road is limited to $400 \mathrm{~m}-\mathrm{by}-400 \mathrm{~m}$ city blocks; giving priority to pedestrians and cyclist and reduce the environmental impacts to vehicles. Figure 1 shows how Superblocks model create a safe outdoor environment that enables children's independent mobility on the street and encourages them to play (Wright, Williams, Hargrave \& Zu Dohna, 2017). This urban idea; children needs is prioritized and encouraged physical activity through everyday freedom between the walkable neighborhood of the superblocks. Indirectly, the trust is within the community, and these pilot project improved the quality of life of children, families and senior citizens. Parents are seen happy and less worry when their children are playing in the middle of the street with no traffic (Roberts,2019). Superblocks is a creative intervention that is appropriate to adopt by local authority in Kuala Lumpur to facilitate the current urban space issue in urban living. For example, the spaces within these superblocks are accessible and provide a mix of uses for the whole community to be active 
and socialize. These intervention supports findings by Wong, et. al 2016, where physical activity supports children' physical and mental health, growth and development, cognitive development, improving self-esteem and academic performance just by having the freedom to be safe in outdoor urban areas. Proper implementation mechanism is needed to assess the suitability as the current housing condition of people's housing scheme is already in cluster of blocks.

\subsection{Safety}

The city of Bogota piloted the children's' priority zone in the city with interventions and traffic calming strategies. The zone focuses on nearby childcare centre with traffic calming, wayfinding and play-street programming. This zone also allows children to have freedom of exploration with ideas like pop up parks, enhanced landscaping, social seating indicating a child-friendly area. In a very dense neighborhood area with minimum open space, these creative interventions is suitable and easy to implement. Global Street Guideline highlighted that streets free from traffic danger promotes active travels that contribute to the greater community. More child-friendly urban space puts people first by focusing on the quality of life (Wright, Williams, Hargrave \& zu Dohna, 2017). Children are vulnerable users of the streets; however, they are equal users of it. Planners and designers are responsible for creating these safe environments for them.

\subsection{Stronger Communities}

All citizens, regardless of their role, are users of public space (Gehl,2011). In a physical environment, the enjoyment of public space involves rights and duties. Social activities take place wherever the quality of the space encourages users to linger, and it is essential to the health and wellbeing of the community. As stated by Dinah, children are the generators of community life. These is also one of the most effective interventions towards the issue. Community need to engaged children and youth as they help to create a more sustainable community by attracting people to the place. However, the physical environment itself needs to be supportive of its activities. Interactions between the young and the old and the presence of children influence motivation for adults to spend time in the public realm (Wright, Williams, Hargrave \& zu Dohna, 2017). Local authority needs to be more creative and tech-savvy in creating a stronger community's approach to bring back the essence of it. As most community today rely more on technology, its has overtaken the previous community engagement program such as Rukun Tetangga, in fact the programme should be rebranded to fit the current lifestyle demand and trend.

\subsection{Conclusion}

A summary of the main findings shows that children are not prioritized in most people's housing in Kuala Lumpur. It is alarming as there are many of the development of people's housing scheme that does not consider the well-being of the community especially children living in the area. The study review some of the concept of best practices from around the world that are seem suitable to be adopted by community and local authority in Kuala Lumpur. A thorough studies and consideration needs to be carried out in order to understand children's' physical environment and their activity needs in the people's housing scheme neighborhood. It raises the questions of challenges of having child-friendly spaces in public housing such as limited space of housing condition which does not support explorations of children's' development holistically. Also, the current condition also limits children's physical and psychological development from opportunities of discoveries as their independent mobility and access to urban green space is limited. Hence, it calls for a suitable assessment towards the mechanism of implementation of urban living issues and solutions. The main benefits of child-friendly urban spaces such as health and wellbeing, safety, and building stronger communities are highlighted from good practices from around the world. Lastly, possible interventions highlighted are small steps one can implement using the creation of intergenerational spaces, playable spaces, safe streets and removing traffic from the street. Future research should, therefore, concentrate on actions, opportunities and measuring the success of child-friendly urban spaces. Outcome of the future research can focus on development of toolkit of solution and guidelines of implementation.

\subsection{Recommendations}

As pointed out in the introduction of this paper, these sections will provide an overview of possible interventions of having child-friendly urban spaces in public housing in Kuala Lumpur. Further research will help to achieve a better vision for implementing it. It must explore the relationship between the different configurations of collective public housing and children's' needs and use of the outdoor spaces. Public space needs to be inclusive and offer a healthy environment (Cabrera-Barona \& Merschdorf, 2018). Some of the possible interventions that can be applied are through small actions leading to the higher impact of change at city's level. In order to make measure the success of these small actions, it needs to be evidence-based and user centered. Here, the context will be well examined from a children's' perspective, and innovative solutions are generated and fit-for-purpose. Some of the possible interventions suggested by Cities Alive Designing for Urban Childhoods; includes creating a community hub that fosters interaction between the young and old. Next, the regeneration of urban spaces through playful interactions by creating playable spaces that also encourages physical activities through everyday freedoms. Public arts also create opportunities for playful encounters for children and the community. Lastly, removing traffic from the street and creating a safe environment for everyday street play and socializing.

\section{Acknowledgements}

The authors would like to thank Taylor's University for supporting this piece of work. 


\section{References}

Collado, S., \& Corraliza, J., A. (2017). Children's Perceived Restoration and Pro-Environmental Beliefs. Journal of ASIAN Behavioural Studies, 2(2), 1-12.

Cabrera-Barona, P., \& Merschdorf, H., (2018). A Conceptual Urban Quality Space-Place Framework: Linking Geo-Information and Quality of Life. Urban Science, 2(3), 73. doi: 10.3390/urbansci2030073

Flouri,E., Midouhas, E., \& Joshi, H. (2014).The role of urban neighbourhood green space in children's emotional and behavioural resilience,Journal of Environmental Psychology,Volume 40,2014,Pages 179-186,ISSN 0272-4944

Gehl Studio NY, J.Max Bond Center, Transportation Alternatives. (2015). Public Life \& Urban Justice in NYC's Plazas (pp. 34-60). New York: Gehl Studio \& JMBC. Retrieved from https://issuu.com/gehlarchitects/docs/nycplazastudy

Ministry Of Housing And Local Government Malaysia. (2011). " Housing In The New Millennium - Malaysian Perspective ". Kuala Lumpur: Jabatan Perumahan Negara.

Mehdi K., \& Koorosh, A. (2015). Achievement to Environmental Components of Educational Spaces for Iranian Trainable Children with Intellectual Disability. Procedia Social and Behavioral Sciences, 201, 9-18.

Sulaiman, N., Ayu Abdullah, Y., \& Hamdan, H. (2017). Street as Public Space - Measuring Street Life of Kuala Lumpur. IOP Conference Series: Materials Science And Engineering, 245, 082025. doi: 10.1088/1757-899x/245/8/082025

Wan Abd Aziz,, W., Haniff, N., Musa, Z., Mohd Aini, A., Sarip, A., \& Zyed, Z. (2014). Vertical Living Phenomenon In Malaysia. Fig Congress 2014

Wong, J., Parikh, P., Poh, B., \& Deurenberg, P. (2016). Physical Activity Of Malaysian Primary School Children. Asia Pacific Journal Of Public Health, 28(5_Suppl), 35s46s. Doi: 10.1177/1010539516650726

Wright, H., Williams, S., Hargrave, J., \& zu Dohna, F. (2017). Cities Alive. London: ARUP.

Zehadul Karim, A. (2013). Living Condition In The Low Cost Apartments In Malaysia: An Empirical Investigation. Asian Social Science, 9(17). Doi: 10.5539/Ass.V9n17p20 